\title{
Illuminating the Brain With X-Rays: Contributions and Future Perspectives of High-Resolution Microtomography to Neuroscience
}

\author{
Paulla Vieira Rodrigues ${ }^{1,2}$, Katiane Tostes ${ }^{1}$, Beatriz Pelegrini Bosque ${ }^{1,2}$, \\ João Vitor Pereira de Godoy,2, Dionisio Pedro Amorim Neto',2, \\ Carlos Sato Baraldi Dias ${ }^{3}$ and Matheus de Castro Fonseca ${ }^{1 *}$

\begin{abstract}
${ }^{1}$ Brazilian Biosciences National Laboratory (LNBio), Brazilian Center for Research in Energy and Materials (CNPEM), Campinas, Brazil, ${ }^{2}$ Department of Structural and Functional Biology, State University of Campinas, Campinas, Brazil, ${ }^{3}$ Brazilian Synchrotron Light National Laboratory (LNLS), Brazilian Center for Research in Energy and Materials (CNPEM), Campinas, Brazil
\end{abstract}

\section{OPEN ACCESS}

Edited by:

Julia Stephen,

Mind Research Network (MRN),

United States

Reviewed by:

Viktor Vegh

The University of Queensland,

Australia

Fahmeed Hyder,

Yale University, United States

${ }^{*}$ Correspondence:

Matheus de Castro Fonseca matheus.fonseca@/nbio.cnpem.br

Specialty section:

This article was submitted to Brain Imaging Methods,

a section of the journal

Frontiers in Neuroscience

Received: 10 November 2020 Accepted: 26 February 2021

Published: 17 March 2021

Citation:

Rodrigues PV, Tostes $K$, Bosque BP, Godoy JVP, Amorim Neto DP, Dias CSB and Fonseca MC

(2021) Illuminating the Brain With

$X$-Rays: Contributions and Future

Perspectives of High-Resolution

Microtomography to Neuroscience.

Front. Neurosci. 15:627994.

doi: 10.3389/fnins.2021.627994
The assessment of three-dimensional (3D) brain cytoarchitecture at a cellular resolution remains a great challenge in the field of neuroscience and constant development of imaging techniques has become crucial, particularly when it comes to offering direct and clear obtention of data from macro to nano scales. Magnetic resonance imaging (MRI) and electron or optical microscopy, although valuable, still face some issues such as the lack of contrast and extensive sample preparation protocols. In this context, $x$-ray microtomography $(\mu \mathrm{CT})$ has become a promising non-destructive tool for imaging a broad range of samples, from dense materials to soft biological specimens. It is a new supplemental method to be explored for deciphering the cytoarchitecture and connectivity of the brain. This review aims to bring together published works using $x$-ray $\mu \mathrm{CT}$ in neurobiology in order to discuss the achievements made so far and the future of this technique for neuroscience.

Keywords: x-ray microtomography, neurobiology, cell tracing, brain architecture, imaging techniques

\section{INTRODUCTION}

Back in the 1970s, the x-ray tomography technique (also known as "computerized axial tomography," "transaxial tomography," and "reconstruction from sections") was first described as a method used in medical radiography for obtaining a slice through the body of the x-ray absorption with a resolution ranging from 1 to about $2 \mathrm{~mm}$ (Hounsfield, 1973; Swindell and Barrett, 1977). This achievement was recognized in the Nobel prize in Physiology or Medicine 1979 (Di Chiro and Brooks, 1979), and since then tomography has been widely used in medical radiology, biological, and material sciences research in order to produce non-invasive, diagnostic, and cross-sectional images of a particular structure within a sample. This technique was further expanded in 1987, when Flannery et al. (1987) developed a so-called "new form of microscopy - microtomography," based on high-resolution x-ray tomography, producing the first three-dimensional (3D) images of the internal structure of small samples with a micrometer resolution. Microtomography $(\mu \mathrm{CT}) \mathrm{can}$ be used to non-destructively create 3D images of internal sections of a sample with a resolution limit comparable to that of a light microscope, allowing not only $3 \mathrm{D}$ visualization but also virtual slicing 
for the obtention of detailed two-dimensional images (2D). Although its roots in computerized axial tomography (CAT or CT) scans have been used for medical imaging for over 40 years, applications of $\mathrm{x}$-ray $\mu \mathrm{CT}$ have been reported for a wide variety of objects (Toda et al., 2008; Chen et al., 2009; Fusseis et al., 2009; Zhu et al., 2011; Tsuchiyama et al., 2013).

In biology, computerized $\mathrm{x}$-ray $\mu \mathrm{CT}$ has provided $3 \mathrm{D}$ images of the architecture of biological samples from many species of organisms including mice (Johnson et al., 2006; Fonseca et al., 2018), humans (Bonse et al., 1994; Salome et al., 1999; Mizutani et al., 2010), and insects (Metscher, 2009; van de Kamp et al., 2011; Smith et al., 2016). It has become a common method in studies associated with osteo and dental microstructures (Neues and Epple, 2008; Zou et al., 2011; Davis et al., 2018). Recently, microtomographic studies of soft tissues, which account for a major proportion of biological tissues, have shed light on the structural mechanism of biological functions (Happel et al., 2010; Walker et al., 2014).

However, when it comes to the usage of $\mathrm{x}$-ray $\mu \mathrm{CT}$ for neuroscience, this method remains to be explored. So far, the primary method for the visualization of high-resolution 3D structures of neuronal tissues is confocal light microscopy. Several transgenic strategies for visualizing neuronal network by genetically labeling neurons with fluorescence dyes have been reported (Sakaguchi et al., 2018; Koveal et al., 2020). Nonetheless, transgenic methods cannot be applied to human samples. Although automated serial sectioning along with light and electron microscopic analyses have been proposed as a method for imaging neuronal circuits (Denk and Horstmann, 2004; Micheva and Smith, 2007; Knott et al., 2008; Tapia et al., 2012; Motta et al., 2019), hundreds to thousands of sections must be mechanically prepared to reconstruct a $3 \mathrm{D}$ structure of a functionally relevant volume of biological tissue, requiring extensive sample preparation protocol.

One of the first usages of $\mathrm{x}$-ray $\mu \mathrm{CT}$ in the neurobiology field was reported back in 1999 when researchers showed the first 3D images of a rat peripheral nerve using synchrotron-based phasecontrast x-ray $\mu \mathrm{CT}$ (Beckmann et al., 1999). However, cellular resolution using this technique was first obtained in 2009, by Mizutani et al. (2010), revealing the first 3D cellular organization of the neuronal circuits of the human cerebral cortex in a biopsy specimen. Since then, some groups have explored the benefits of this technique to unveil the architecture and organization of neuronal tissues.

Therefore, this review aims to bring together published works using x-ray $\mu \mathrm{CT}$ in neurobiology in order to discuss the achievements made so far and focus on the future of this technique as a promising tool to provide more information about the structural and functional organization of the brain in this current connectomics era.

\section{THREE-DIMENSIONAL IMAGING TECHNIQUES IN NEUROBIOLOGY}

The systematic microscopic study of neurons as individualized entities has its beginning in the 19th century with the development of the Golgi staining protocol based on silver impregnation (Golgi, 1873). Before that, early microscopists had studied peripheral nerves and spinal tracts in search for hollow tubes that would hypothetically conduct a fluid abundant with signals from the skin to the brain, and from the brain and spinal cord to muscles (Glickstein, 2006). By the year 1887, using the Golgi staining method, Ramón y Cajal (1911) changed the way neurons were seen (Glickstein, 2006) with his observations and descriptions:

"Against a clear background stood black threadlets, some slender and smooth, some thick and thorny in a pattern punctuated by small dense spots. All was sharp as a sketch with Chinese ink on transparent Japanese paper."

From this moment on, neuroscientists from all over the world opened the gate of modern neuroscience and improved not only neuroscience itself but also the development of new $2 \mathrm{D}$ and 3D imaging techniques in order to explore neural circuits and microscopic anatomy. Imaging has become an important and elusive tool for basic and clinical research due to offering direct and clear obtention of data regarding brain architecture and biochemical activities from macro to nano scales (Ganesana et al., 2017). Over the last few decades, optical methods such as confocal (Erturk et al., 2014) and two-photon microscopy (Oheim et al., 2001; Nimmerjahn, 2012), associated with the use of fluorescent dyes and transgenic fluorescent animals, allowed for not only the morphological analysis of neuronal cells and tissues, but also revealed important biochemical and physiological characteristics of these structures. In addition, in vivo imaging has been extensively developed, for example, with two-photon excitation microscopy in the open-skull mouse (Grutzendler et al., 2011; Nimmerjahn, 2012). However, brain tissue is a strong lightscattering medium, which makes it difficult to focus the excitation light on a small target point and detect the emitted signal. Based on this, several optical methods, including BABB (Dodt et al., 2007), SeeDB (Ke and Imai, 2014), Clear (T) or Clear (T2) (Kuwajima et al., 2013), and 3DISCO (Erturk et al., 2012, 2014; Erturk and Bradke, 2013) were developed for 3D imaging.

Nevertheless, axons and dendrites of neurons extend in many directions, some interneurons crossing several millimeters through a huge volume of brain mass, what leads to incomplete tracing and difficulties in the reconstruction of 3D morphology of isolated cells in the whole brain parenchyma. To overcome this, methods for resolving the 3D microstructure of large brain regions are typically based on thin serial slicing and staining of brain sections, followed by imaging numerous individual slices with light or electrons. Although valuable, these procedures still face some issues such as lack of contrast, extensive sample preparation protocols, and the destructive nature of serial sectioning.

As another widely used imaging approach in several fields of science, from bench to the bedside, magnetic resonance imaging (MRI) is also part of the group of methods used for the study of the nervous system, in its three dimensions. Today, MRI can provide numerous contrast modes for various analyses starting at the anatomical contrast between white and gray substances in the central nervous system to tractography or diffusion tensor 
imaging (Vedantam et al., 2013) to visualize nerve tracts within the brain. The applicability of this technique directly relates to obtaining $2 \mathrm{D}$ and $3 \mathrm{D}$ structural or functional scanned images of the tissue (Bernard et al., 1988, 2016; Kuehne et al., 2004). However, this approach is an expensive technique, in which image processing is complex and requires time and qualified personnel. In addition, although the imaging of entire structures such as the human cerebellum (Topperwien et al., 2018) could be obtained in vivo, the spatial resolution offered by MRI is described as unsatisfactory to study neuronal structures on a cellular/subcellular scale (Schulz et al., 2010; Schulze et al., 2010).

Therefore, new 3D imaging procedures are still needed to assess increasingly larger brain volumes at the single cell level which makes the use of $\mathrm{x}$-rays an interesting new approach. $\mathrm{X}$-rays can be used to image thick samples, providing a rapid approach for producing large $3 \mathrm{D}$ brain maps without sectioning (Figure 1). Hence, to reconstruct the 3D in situ morphology of neurons, $\mathrm{x}$-ray $\mu \mathrm{CT}$ became a promising tool.

\section{HIGH-RESOLUTION MICROTOMOGRAPHY FOR THE STUDY OF THE NERVOUS SYSTEM}

As previously mentioned, $\mathrm{x}$-ray $\mu \mathrm{CT}$ has been broadly applied for a great number of biological structures especially hard tissue samples such as bones and teeth (Neues and Epple, 2008; Schulze et al., 2010; Zou et al., 2011; Davis et al., 2018). Although still not deeply explored, microtomographic analyses of soft tissues, including nervous tissue, can reveal the functional mechanisms of 3D cellular and subcellular structures based on its spatial organization and distribution (Figure 2). A great example of the importance of spatial organization for organ functioning is well represented by neuronal networks. Understanding how neurons are connected and distributed, from macro- to microscale, is fundamental to unveil brain architecture, functioning, and dynamics.

$\mathrm{X}$-ray $\mu \mathrm{CT}$ imaging does not require that tissues undergo serial-sectioning or any type of physical processing, i.e., the sample remains completely undamaged, which guarantees that the neuronal circuit is intact and leads to the possibility of building 3D models that have a higher level of detail and resolution (Figure 3).

$\mathrm{X}$-ray imaging based on pure absorption dates back to the discovery of x-ray itself (Zhang and Fuller, 1998). However, a key challenge for using $\mu \mathrm{CT}$ methods for brain imaging is its transparency to $\mathrm{x}$-rays (Masis et al., 2018), thus rendering limited contrast between the different structures within the tissue. Nonetheless, some approaches have already been used to overcome this issue: $\mathrm{x}$-ray fluorescence for elemental imaging and phase contrast and high-z element absorption.

\section{Scanning X-Ray Fluorescence Microtomography}

Scanning X-ray fluorescence (SXF) $\mu$ CT works in a similar way to a confocal optical microscope as it uses a focused $\mathrm{x}$-ray beam and a scanning probe that detects the fluorescence of a given chemical compound. The essential difference between $\mathrm{x}$-ray fluorescenceCT and conventional CT is that the measurement is not based on the absorption of the incoming $\mathrm{x}$-ray but on the measurement of the fluorescent $\mathrm{x}$-rays generated by a specific chemical element of the sample once illuminated, with the ultimate purpose of reconstructing $3 \mathrm{D}$ compositional variations (Figure 1).

Therefore, the measured $\mathrm{x}$-ray fluorescence corresponds to a unique "fingerprint" of a chemical element that provides multiple contrast channels, each related to a different element. It is reported that $\mathrm{x}$-ray fluorescence of a probe element down to a concentration of 1 ppm can be visualized in 3D (Lanzirotti et al., 2009). For intracellular imaging of probe elements (especially transition metals) in delicate biological samples such as brain tissue, recent instrumentation advances in intense $\mathrm{x}$-ray beams of synchrotron $\mathrm{x}$-ray facilities have allowed researchers to achieve nanometer spatial resolution with sub-ppm detection limits for a wide range of elements that may be present in the normal or malfunctioning brain (Collingwood and Freddy, 2017).

The rationale for investigating elementary composition in the brain is diverse. The excellent sensitivity and specificity achievable with fluorescence $\mathrm{x}$-ray microscopy (XRM) allow for the investigation of metal toxicity, for example, from environmental exposure to heavy metals (Md Khudzari et al., 2013). Some studies have also used this technique to investigate the normally functioning brain and disease-mediated changes due to the storage and metabolism of biologically essential metal elements in specific intracellular compartments or as widespread accumulation in the brain. For example, Ortega and collaborators have shown that iron accumulates into dopamine neurovesicles and this process is inhibited by decreased dopamine synthesis (Ortega et al., 2007). In addition, using $\mathrm{x}$-ray fluorescence imaging in conjunction with regular optic microscopy approaches, Carboni et al. (2017) have shown a pronounced difference in trace metal composition of Parkinson's disease brain samples when compared to the control.

\section{Phase-Contrast Microtomography}

Contrary to absorption contrast $\mu \mathrm{CT}$, phase-contrast methods can provide increased contrast toward soft tissues as has been shown for a huge array of biological samples (Beckmann et al., 1999; Betz et al., 2007; Chen et al., 2009; Connor et al., 2009a,b; Bravin et al., 2013; Takashima et al., 2015; Topperwien et al., 2018, 2019; Massimi et al., 2019; Shi et al., 2019). Phase contrast aims to exploit the fact that, in the $\mathrm{x}$-ray's regime, matter is approximately 1,000 times more efficient at refracting than absorbing the $\mathrm{x}$-ray wave. Currently, synchrotron-based phasecontrast imaging partially utilizes coherent $\mathrm{x}$-rays together with an area detector for recording the phase shift due to abrupt change on material found on sample edges. This approach is essentially different from scanning techniques as it illuminates the whole sample recording a single frame for each projection (Figure 1), making the acquisition considerably faster. Therefore, phase-contrast $\mathrm{x}$-ray imaging is especially appropriate for highthroughput $3 \mathrm{D}$ characterization of microstructures in biological samples with low $\mathrm{x}$-ray absorption without the need of contrast agents (Bravin et al., 2013; Zhang et al., 2015). 
A

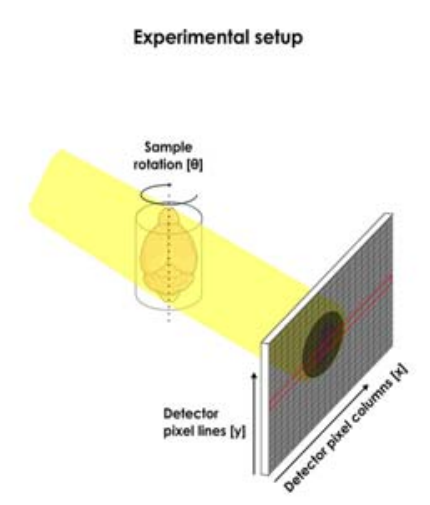

C

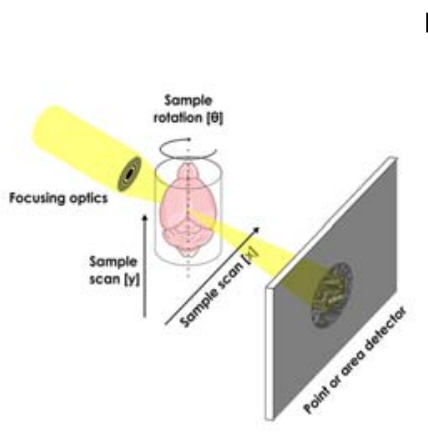

B

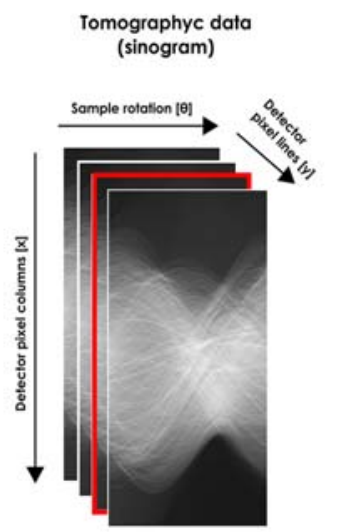

D

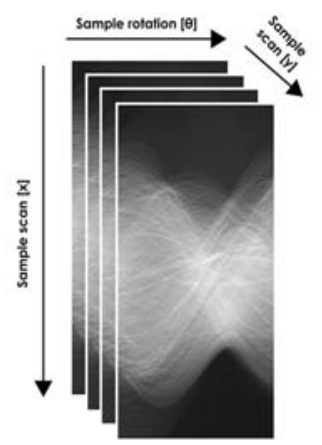

$\mathbf{F}$

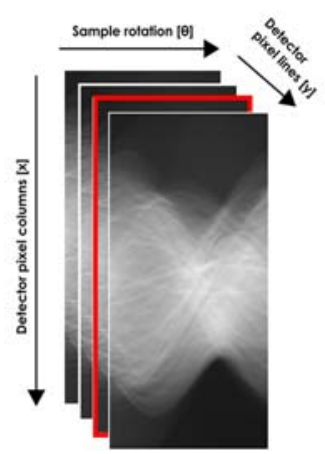

G
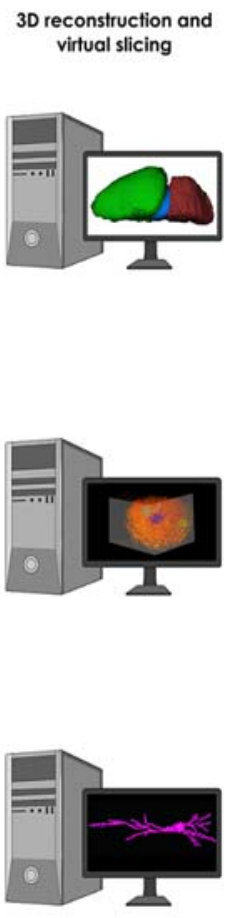

FIGURE 1 | Experimental setups for the structural x-ray microtomographic imaging of the nervous system. (A) Schematic view of the experimental setup for synchrotron-based $\mathrm{x}$-ray single-frame $\mu \mathrm{CT}$. The $\mathrm{x}$-ray from an x-ray source illuminates the whole sample and an x-ray area detector like a CCD (as portrayed), or an x-ray objective-based system (not shown) collects the transmitted projection. (B) Recorded single-frame projections organized as a sinogram. (C) Schematic view of the experimental setup for scanning synchrotron-based x-ray $\mu \mathrm{CT}$. The $\mathrm{x}$-ray from an $\mathrm{x}$-ray source is focused on a single point of the sample and a detector collects the signal from a single pixel. The beam scans the whole sample in order to compose an image. (D) Recorded scanning projections organized as a sinogram. (E) Schematic view of the experimental setup for phase-contrast synchrotron-based x-ray single-frame $\mu$ CT. (F) Recorded single-frame projections organized as a sinogram. In this case, no contrast agent is used during sample preparation and a tomogram is acquired based only on natural contrast of the tissue. An area detector is used for recording the phase shift due to abrupt change in material found on the sample edges. (G) After tomographic reconstruction, the obtained tridimensional data can be virtually segmented or sliced for analysis. Cartoons used were obtained from public domain libraries available under the Creative Commons CCO License (https://creativecommons.org/publicdomain/zero/1.0/).

In neuroimaging, the potential of $\mathrm{x}$-ray phase-contrast tomography as a large-scale, label-free, 3D imaging technique has been exploited in a number of recent studies. For example, 3D angioarchitecture of the mouse brain at ultrahigh resolution was revealed using synchrotron-radiation-based propagation phasecontrast imaging (Shi et al., 2019). The effects of ischemic stroke induced in a mouse model by reconstructing the 3D density within the brain tissue was also recently shown (Topperwien et al., 2019). The cerebral angioarchitecture was visualized within large brain regions of rats by Zhang and collaborators (Zhang et al., 2015). Tissue alterations in different disease states, for example neuronal loss and vascular alterations in a multiple 


\section{A}

\section{X-ray source}

\section{High-resolution image of a cortical neuron in the intact mouse brain}

B

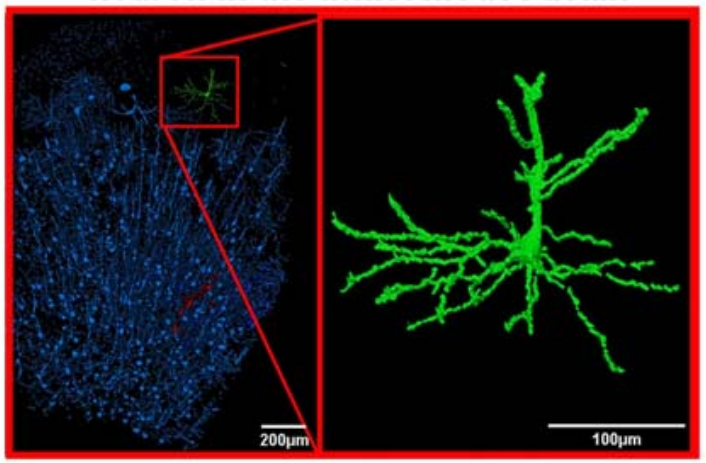

Myelinated axons of a mouse brain tissue

C

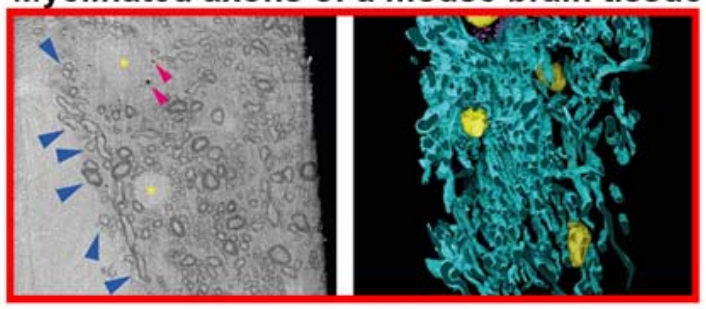

3D surface of a Purkinje cell from human cerebellum

D

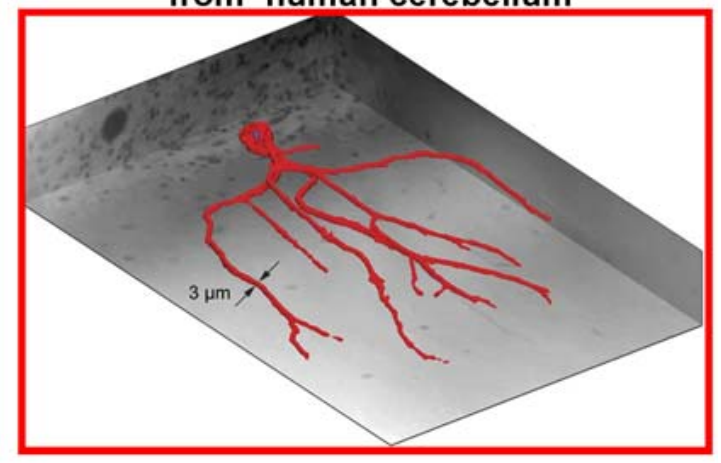

Structure of bumblebee brain

E

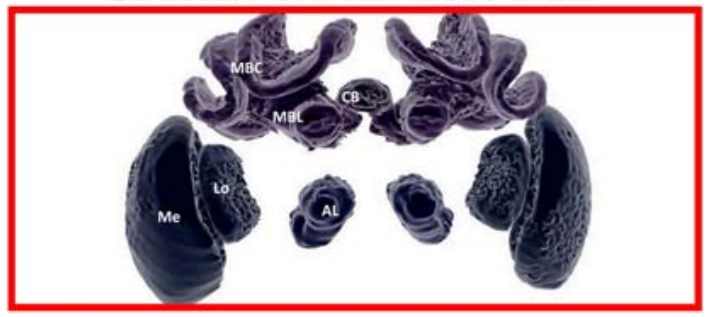

FIGURE 2 | Different $x$-ray microtomography techniques provide detailed three-dimensional information about nervous tissue architecture in high-resolution. (A) The $\mathrm{x}$-ray from an x-ray source can be used to illuminate different samples of nervous tissue from different organisms. (B) High-resolution image of a highlighted cortical neuron (green) from the intact mouse brain (Fonseca et al., 2018). (C) Cryo x-ray ptychography and 3D color rendering of mouse brain tissue. (Left panel) represents a single orthoslice from a reconstructed 3D tomogram. Blue arrowheads show variations of myelin sheath thicknesses of myelinated axons. Yellow asterisks mark multiple cell nuclei and small and roughly spherical structures are pointed by arrowheads. (Right panel) portrays the semi-automated color segmentation of the reconstructed tomogram shown in the left panel, based on the contrast differences within the sample. Yellow = nuclei, blue = myelinated axons (Shahmoradian et al., 2017). (D) Representation of the 3D surface of a Purkinje cell in the human cerebellum including its dendritic tree (Hieber et al., 2016). (E) 3D image of individually segmented brain structures of the bumblebee (Bombus terrestris): central body (CB), and one of the pair of lobulas (Lo), medullas (Me), antennal lobes (AL), mushroom body calyces (MBC), and mushroom body lobes (MBL). This figure was adapted from Hieber et al. (2016); Smith et al. (2016), Shahmoradian et al. (2017); and Fonseca et al. (2018) under the Creative Commons License 4.0 (CC-BY) (http://creativecommons.org/licenses/by/4.0/). Cartoons used were obtained from public domain libraries available under the Creative Commons CCO License (https://creativecommons.org/publicdomain/zero/1.0/). 

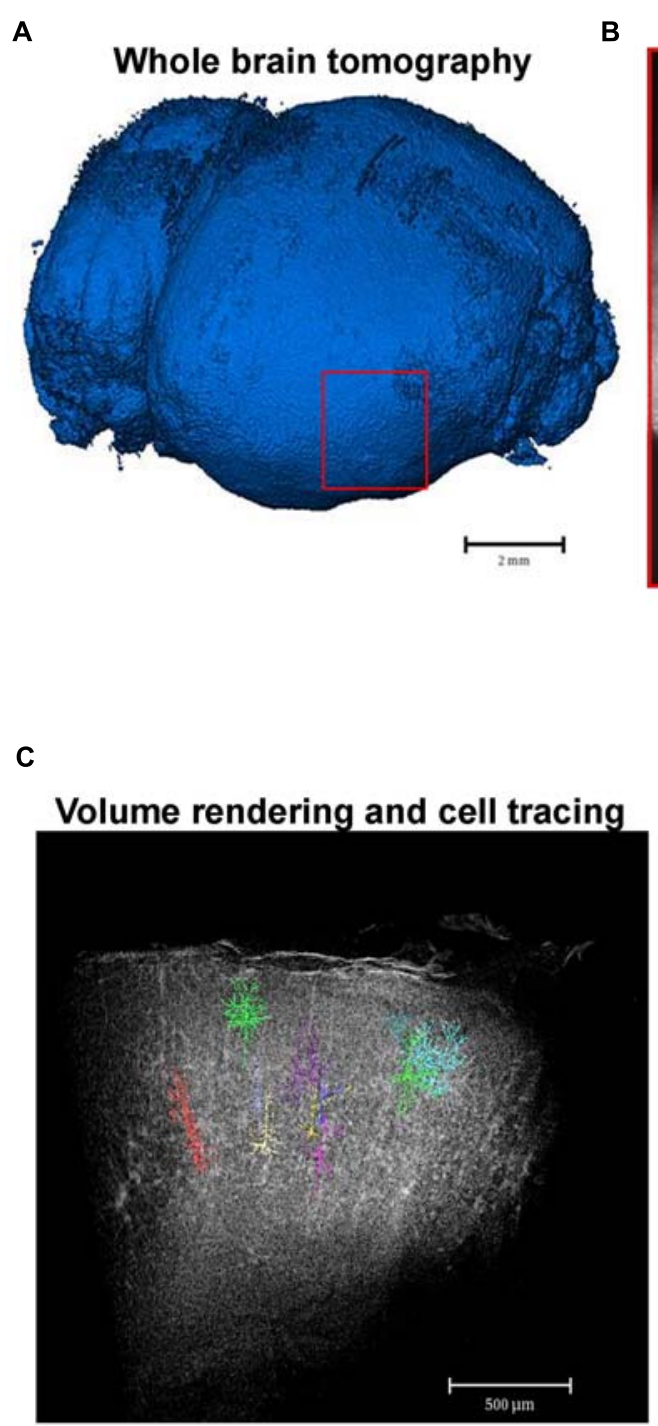

B

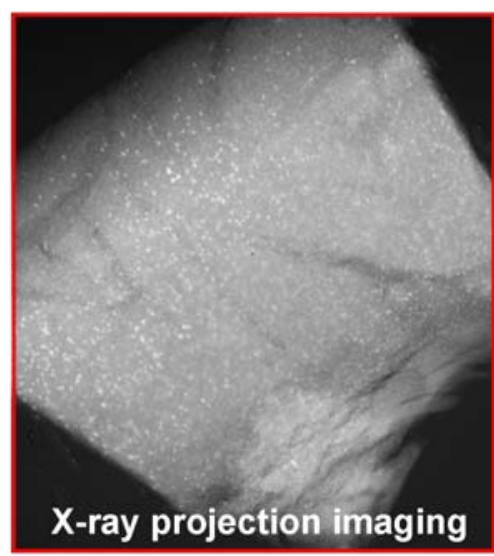

D

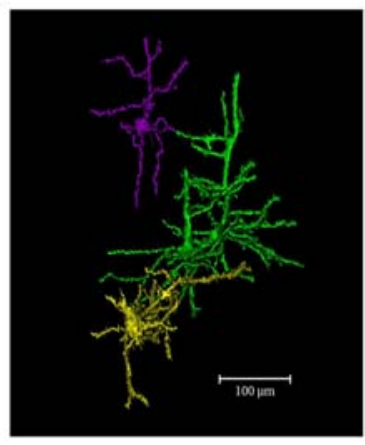

E

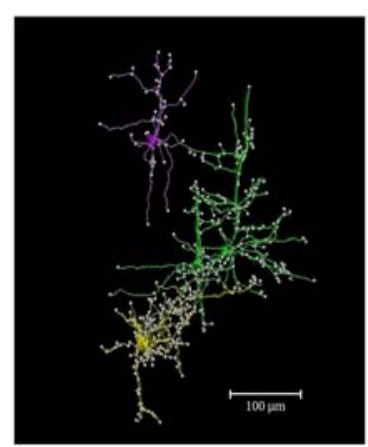

FIGURE 3 | From macro- to microscale imaging in the same set of image acquisition. X-ray $\mu$ CT allows for the acquisition of images from whole intact organs which can then be virtually sliced and analyzed in a microscale. (A) Whole tomography of a paraffin-embedded mouse brain. Red square shows the region of interest to be analyzed in a high-resolution microscale. (B) X-ray absorption projection of Golgi-Cox-labeled brain region selected in panel (A). Bright spots represent successfully mercury-impregnated neurons. (C) Volume rendering of the whole region selected in panel (A) showing some segmented neurons within the structure. (D) Cellular segmented neurons of the structure represented in panel (C). Colors highlight a single neuron or a cluster of cells that could not be separated due to close proximity. (E) Example of analyzes of neuronal branching patterns. Each white dot represents a cell branch.

sclerosis model (Cedola et al., 2017), or plaque formation in Alzheimer's disease models (Astolfo et al., 2016; Massimi et al., 2019) have also been addressed. This technique was also applied to ex vivo whole brain scans in view of brain tissue morphology for both normal and cancerous tissue, before and after x-ray microbeam radiation therapy (Barbone et al., 2018). A study conducted by Saiga et al. (2019) evaluated the brain and spinal cord of mice with autoimmune encephalomyelitis by x-ray $\mu \mathrm{CT}$ using synchrotron radiation, demonstrating that the spinal cord of animals affected by this condition had a pronounced tissue inflammation portrayed by the observed dilated vessels and vacuolization, the latter also being found in the cerebellum (Saiga et al., 2019). The subsequent reconstruction of a 3D model for the vessels and vacuoles network found that the distribution of vacuoles is not uniform and the more severe the state of the disease, the greater the vasodilatation. Finally, a study by Luo et al. (2019) analyzed brain samples from mice subjected to ischemia and described a new methodology that allowed the 3D analysis of 
the vascular repair in the ischemic lesion, both qualitatively and quantitatively, so that the morphology of the micro vessels could be visualized after the reconstruction of the vascular skeleton (Luo et al., 2019).

In spite of being a label-free method, resolution and contrast were demonstrated to be sufficiently good for single cell identification in larger volumes both for rodents (Fratini et al., 2015; Bukreeva et al., 2017, 2020) and for human tissues (Hieber et al., 2016; Khimchenko et al., 2018; Topperwien et al., 2018).

\section{X-Ray Absorption Microtomography Using High-z Probes}

High z-probes are contrast agents featuring high-atomic-number (high-Z) elements which absorb x-rays effectively. Examples of these probes that have already been reported for visualizing biological microstructures include osmium (Ananda et al., 2006; Johnson et al., 2006; Litzlbauer et al., 2006; Dias et al., 2019), gold (Mizutani et al., 2007, 2008, 2010; Li et al., 2010), silver (Mizutani et al., 2008; Parameswaran et al., 2009), iodine (de Crespigny et al., 2008; Metscher, 2009), platinum (Wang et al., 2017), mercury (Fonseca et al., 2018; Nani et al., 2020), tungsten (Metscher, 2009), and lead (Kamenz and Weidemann, 2009). The advantage of this method is the clear visualization of structures that may not be well delimited only by phase contrast.

So far, recent studies have used high resolution $\mu \mathrm{CT}$ to characterize 3D high-z-labeled structures that make up the central nervous system in various species (Figure 2). Mizutani et al. (2010), using Golgi's impregnation method, have successfully observed pyramidal neurons, interneurons, and blood vessels within a human cortex brain sample (Mizutani et al., 2010). Using the mouse brain, Depannemaecker et al. (2019) achieved the observation of the blood vessels, brain cortex, lateral ventricle, and cell bodies of neurons (Depannemaecker et al., 2019). Furthermore, the in situ morphological characterization of individual neurons in specific brain regions followed by a quantification of cell number from a large volume of the hippocampal tissue, collected from healthy and pilocarpine-treated mice, was recently shown by impregnating the samples with Golgi-Cox solution. This approach was based on impregnating neurons with mercury which enabled a virtual histology, an integrated 3D visualization of the neuronal network, and a 3D quantification of a large portion of tissue (Fonseca et al., 2018; Figures 3, 4). This work was the first to provide visualization of the complete single cell morphology of intact neuronal tissues with $\mathrm{x}$-ray $\mu \mathrm{CT}$. In addition, using the Golgi-Cox impregnated samples from a rat model with dysfunctional disrupted-in-schizophrenia1 signaling, the assessment of neuronal cell body number and the spatial organization of brain neurons revealed defective neuronal positioning, characteristic of impaired cell migration, in striatum/nucleus accumbens and the prefrontal cortex compared to wild-type brains (Nani et al., 2020). Dyer et al. (2017), in turn, identified the 3D architecture of neurons and glia cell bodies, vasculature, large segments of apical dendrites, and myelinated axons via staining of brains with heavy metals (Dyer et al., 2017).
Another type of sample widely used in $\mu \mathrm{CT}$ neuroimaging is Drosophila melanogaster brains impregnated with heavy metals such as gold and silver. Some studies have resulted in the construction of a 3D model of the neural network skeleton of this organism that could allow for the obtention of valuable information about the functional mechanisms of the brain (Mizutani et al., 2007, 2008). Recently, the obtention of images using a combination of $\mathrm{x}$-ray absorption and phase-contrast effects was reported (Chin et al., 2020). Specifically, for the portion of the neurons labeled by the Golgi-Cox staining in each specimen, absorption contrast dominated. Instead, other features like the Drosophila skull are primarily revealed by phase contrast. This difference facilitates the reliable identification of stained neurons and other neuron-related structures.

\section{PERSPECTIVES}

\section{Instrumentation}

The contribution to neuroscience development using $\mathrm{x}$-rays, especially based on synchrotron radiation, is deeply related with the development of XRM in its various forms. It is well known that the deep relation between the shape and function of biological structures makes the brain one of the most complex hierarchical structures found in nature with significant structures down to the sub-cellular level. Accordingly, those structures can only be fully understood if a proper $3 \mathrm{D}$ imaging technique is available. Within this context, XRM refers to a collection of imaging techniques with enough spatial resolution and high penetration power for $3 \mathrm{D}$ imaging.

All these approaches rule out the need for fluorescence dyes and complex sample preparation. Nonetheless, XRM is still in an initial state of development creating the necessary tools focusing not only on instrumentation but also on sample preparation and mounting protocols (Dias et al., 2019).

Different types of XRM such as full-field $\mathrm{x}$-ray microscopy and ptychography can provide improved spatial resolution when compared to super-resolution optical microscopy. Also, advanced contrast modes exploring chemical speciation and nanoscale assembly would provide new $3 \mathrm{D}$ mapping of brain tissue organization. From the sample preparation perspective, the development of specific staining procedures would allow functional imaging similar to light microcopy but with increased resolution.

\section{Spatial Resolution}

$\mathrm{X}$-ray microscopy can be divided into two main categories: single frame, where an entire image is collected with a single exposure; and scanning, where each pixel on the image is measured individually (Figure 1). Naturally, the former is considerably faster than the latter and in the case of tomography, when a collection of multiple images is necessary, the acquisition time of a single image rapidly scales and becomes of great importance.

Recent developments in $\mathrm{x}$-ray optics have allowed the production of $\mathrm{x}$-ray objectives, opening the way for a lens arrangement similar to an optical microscope. This technique offers rapid nanoscale $\mathrm{x}$-ray imaging capability, meaning 
A
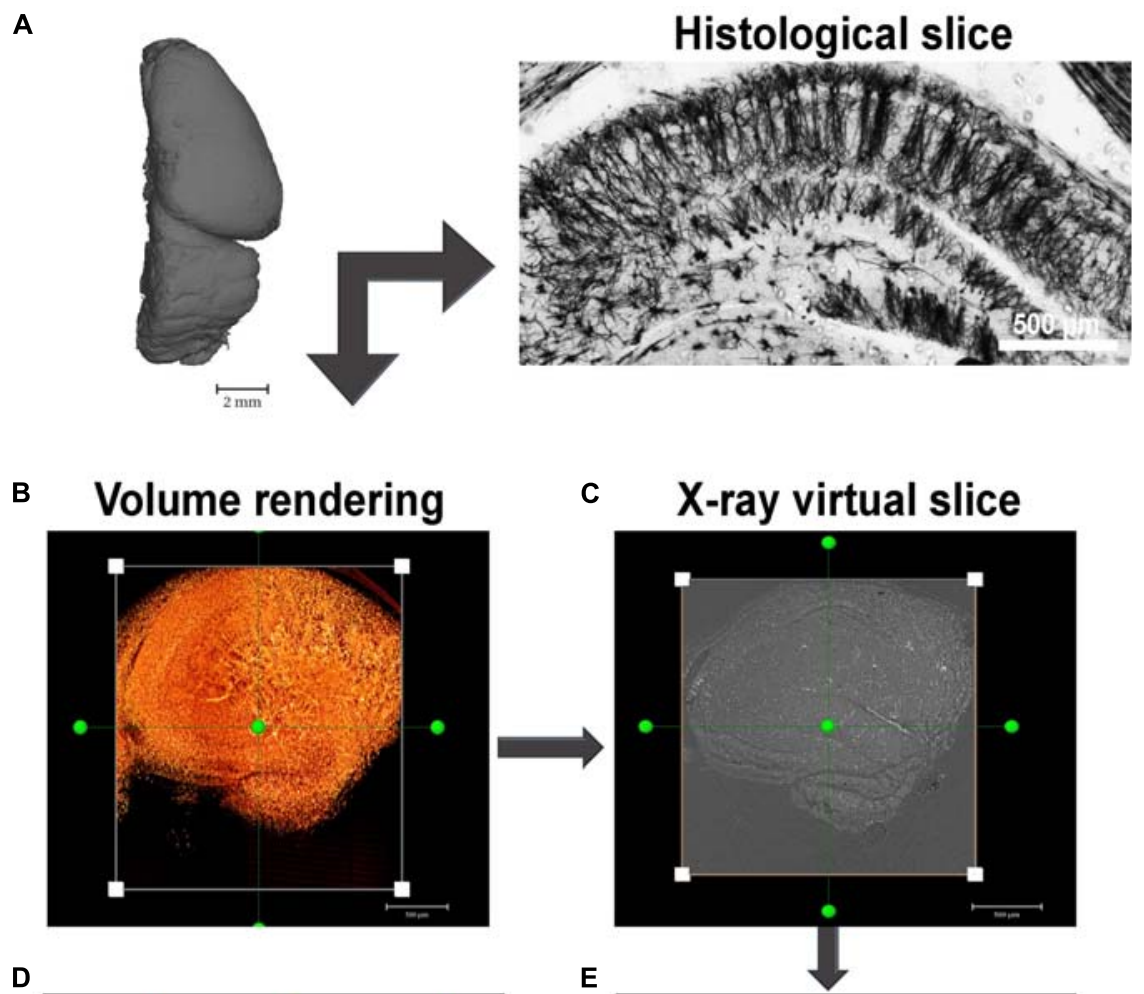

D
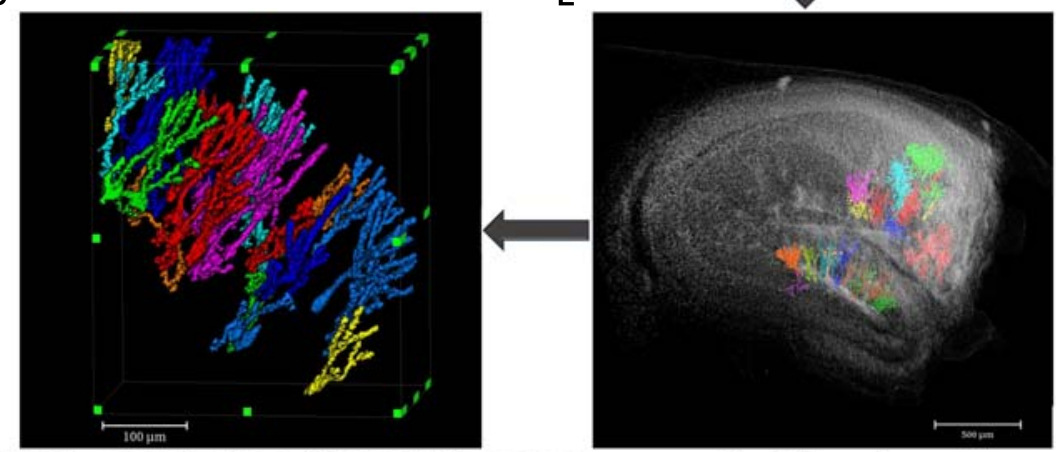

High-resolution 3D cell tracing Cell tracing

FIGURE 4 | Virtual histology in 3D with x-ray absorption microtomography. (A) A paraffin-embedded mouse hemisphere after Golgi-Cox staining and embedded in paraffin can be seen by histology or $x$-ray microtomography. Far right image shows a histological section of a Golgi-Cox-impregnated mouse hippocampus exhibiting the neurons of the sliced structure evenly and reliably stained. (B) This image shows a 3D image rendering of a Golgi-Cox-impregnated mouse hippocampus. (C) Virtually reconstructed image of one slice of the rendered image represented in panel (B). (D) Volume rendering of some selected slices of the tissue shown in panel (A) where some neurons were segmented. (E) High-resolution image of segmented neurons located at the dentate gyrus of the mouse hippocampus imaged in panel (B).

tomographic acquisitions in the order of minutes per sample (Weinhardt et al., 2019) and a spatial resolution as small as $20 \mathrm{~nm}$. So far, most of the advances for this approach were made in the soft $\mathrm{x}$-ray energy range (named water window) for exploring the existent natural contrast between protein and water within this energy range. However, this also limits the $\mathrm{x}$-ray penetration depth to $10 \mu \mathrm{m}$ making this a suitable tool for single cell image only (Sakdinawat and Attwood, 2010; Hemonnot and Koster, 2017). For tissue samples, high energy x-ray microscopes would allow for the imaging of samples as big as $1,000 \mu \mathrm{m}$ but with the cost of losing the absorption contrast for biological samples. However, as demonstrated by Holzner et al. (2010), hard x-ray full-field microscopes can be equipped with a Zernike phase plate (ZPP) for phase contrast. Indeed, Yang et al. (2010) and Vartiainen et al. $(2014,2016)$ have demonstrated that this approach is able to achieve a spatial resolution of $50 \mathrm{~nm}$ on biological samples.

However, the hierarchical structure of a brain also presents structures that are smaller than $50 \mathrm{~nm}$. In that sense, the use of high $\mathrm{x}$-ray with shorter wavelengths would also contribute toward increasing resolution. Current developments on XRM still limit hard $\mathrm{x}$-ray full-field imaging to a $30 \mathrm{~nm}$ resolution 
(Weinhardt et al., 2019), especially due to hard x-ray lens quality since higher energy $\mathrm{x}$-ray optics are much more challenging to manufacture. This led to the independent development of lensless XRM techniques known as coherent diffraction imaging (CDI; Lo et al., 2018; Nakasako et al., 2020). These techniques can achieve a substantially better spatial resolution by eliminating the need for a hard $\mathrm{x}$-ray objective, which is promising for the visualization of neuronal structures much smaller than $50 \mathrm{~nm}$. In general, CDI measures the scatted $\mathrm{x}$-ray wave of a sample meaning the sample's phase information will be encoded in the form of a diffraction pattern. By measuring this pattern on an area detector, the sample can be reconstructed using specialized phase retrieval algorithms. Likewise, the phase retrieval algorithms together with the area detector, replace the need for an objective lens. On the other hand, CDI depends on a highly coherent $\mathrm{x}$-ray source, meaning CDI-based XRM usage is restricted to synchrotron-light facilities.

There are several CDI methods namely plane-wave CDI, Bragg CDI, and ptychography, among others (Lo et al., 2018; Nakasako et al., 2020). Ptychography is a scanning microcopy technique consisting of a series of diffraction patterns from partially overlapping regions that allows for robust image reconstruction with both absorption and phase-contrast imaging (Stockmar et al., 2015). Examples of both 2D imaging (Gallagher-Jones et al., 2017) and 3D ptycho-tomography of cells (Deng et al., 2018) already attest for the feasibility of the technique on achieving resolutions below $20 \mathrm{~nm}$ on biological samples. It is worth mentioning a work done by Shahmoradian et al. (2017). In this work, the authors used hard $\mathrm{x}$-ray ptycho-tomography to image a chemically fixed mouse brain tissue in a frozen-hydrated state without heavy metal staining and reached a $3 \mathrm{D}$ resolution of $\sim 120 \mathrm{~nm}$ on a volume of $48 \mu \mathrm{m}^{3}$ during a 23 -h imaging acquisition. Such time-consuming measurement is due to the scanning characteristic of the technique. However, with the new 4th generation synchrotron sources already in operation the coherent photon flux necessary for this type of experiment should increase 1,000-fold, meaning 1,000-fold faster experiments.

\section{Specific Staining}

So far, few cell- or tissue-specific contrast agents for $\mu \mathrm{CT}$ are reported in literature (de Bournonville et al., 2019). Therefore, the development of novel tissue-specific contrast agents still needs to be widely explored in this field. An attempt in that direction was beautifully performed with whole kidney eosin-based staining. In this work, the authors presented a cytoplasm-specific staining method tailored for $\mathrm{x}$-ray $\mu \mathrm{CT}$ that enables a routine and efficient 3D volume screening at high resolutions (Busse et al., 2017).

Following this cell-specific contrast agent idea, some studies demonstrated the applicability of $40-\mathrm{nm}$ biocompatible bismuth particle cores encapsulated in poly(lactic-co-glycolic acid) (PLGA) (Naha et al., 2014; Swy et al., 2014; Zhu et al., 2014) that enabled efficient targeting of the particles to cancer cells that overexpress folic acid receptors. These labeled cells could then be imaged in vitro or in vivo in a xenograft tumor model (Zhu et al., 2014). Another reported example is the use of iron nanoparticles for single cell visualization (Kim et al., 2017). Because of the limited spatial resolution and low affinity of the nanoparticles to the cells, the minimum number of detectable cells was 50,000 within muscle samples. In addition, the nanoparticles needed to be administered inside the cells before implantation in the tissue, questioning the potential cytotoxicity of this method as an effective contrast agent.

In neurobiology, the examples are even scarcer. Although several contrast agents are used to label nerve tissues for $\mu \mathrm{CT}$ these reagents stain neurons randomly, which makes it impossible to distinguish among specific neuronal populations based on neurotransmitter content, for example. Recently, one technique showed that 20 -nm gold nanoparticles conjugated to antibodies, routinely used in the immunohistochemistry method, to specifically label neuronal nuclei (Depannemaecker et al., 2019). However, resolution was very low, and improvements are necessary to increase image quality and the application of this method. Hence, future developments should focus on designing, synthesizing, and evaluating new high-affinity, neuron-specific contrast agents. Some possibilities may be considered, for example, the development of contrast agents for $\mathrm{x}$-ray that bind specifically to membrane proteins or that are transported to the cytoplasm by specific membrane transporters, which would generate so-called "immunological imaging." To the best of our knowledge, literature regarding immunological imaging in $\mu \mathrm{CT}$ is, however, premature. This $3 \mathrm{D}$ high-resolution immunospecific-based $\mu \mathrm{CT}$ can be highly valuable since it could provide relevant information about the spatial distribution of specific cell types, proteins, or antigens within 3D heterogeneous tissues. Because of the high potential of these novel protein/antigenspecific contrast agents, we believe that this approach should be deeper explored and will generate groundbreaking findings from their use in neurobiology.

\section{Imaging Analysis}

Although constant refinement and development of imaging acquisition methods are in progress, future directions in the development of $\mu \mathrm{CT}$ for biological research must also focus on developing computational and analytical tools in order to make full use of the power of quantitative 3D images. Computational reconstruction of neural circuits within tissues from big volume data such as those obtained by $\mathrm{x}$-ray $\mu \mathrm{CT}$ require the tracing of cells in their totality, including all their neurites. Most of the automated approaches that have been developed so far for cell tracing still face some considerably high error rates in order to generate reliable circuit diagrams and demand extensive human supervision. Although most of the analytical approaches used for 3D image analysis of big volume data were developed for electron microscopy images, several can also be applied to $\mu \mathrm{CT}$ data, as will be discussed.

A flood-filling network, for example, is a method developed for automated segmentation that uses convolutional neural networks together with a recurrent pathway that allows for the iterative optimization and extension of individual neuronal processes (Januszewski et al., 2018). Another promising method named SegEM was recently presented and consists of a toolset for efficient semi-automated analysis of large-scale fully stained 3D-EM datasets for the reconstruction of neuronal circuits (Berning et al., 2015). By combining skeleton reconstructions of the imaged neurons with automated volume segmentation, 
this toolset allows for the reconstruction of neuronal circuits at a work hour consumption rate of about 100-fold less than that necessary for manual analysis and about 10 -fold less than existing segmentation tools, as stated by the authors.

In addition to imaging analysis, ongoing advances in tomographic reconstruction algorithms (Padole et al., 2015) are allowing high-quality data to be collected with lower doses and in shorter timescales, which is of particular importance to $\mu \mathrm{CT}$ studies of biological soft tissues especially dynamically changing living tissues.

\section{CONCLUDING REMARKS}

Although in development for over 50 years, the $\mu \mathrm{CT}$ field is still very young, but with high potential for biomedical research, especially for neuroscience. Until now, x-ray $\mu \mathrm{CT}$ applied to biological samples has revealed in situ cellular/subcellular structures and their spatial distribution in a $3 \mathrm{D}$ matrix that are fundamental to understanding features of an organ that are relevant to many biological functions. However, the convergence of sciences for the physics of x-rays, $\mathrm{x}$-ray microscopy, biology, and $3 \mathrm{D}$ structure analysis in neuroscience still need to be thoroughly explored with the promise to break new ground using this interdisciplinary approach.

To our knowledge, this is the first integrative review that gathered published works focusing on $\mu \mathrm{CT}$ applied to neurobiology. One can see that there is a strong need for the development, optimization, and validation of specific contrast methods when it comes to heterogeneous tissues such as the

\section{REFERENCES}

Ananda, S., Marsden, V., Vekemans, K., Korkmaz, E., Tsafnat, N., Soon, L., et al. (2006). The visualization of hepatic vasculature by X-ray micro-computed tomography. J. Electron. Microsc. 55, 151-155. doi: 10.1093/jmicro/dfl015

Astolfo, A., Lathuiliere, A., Laversenne, V., Schneider, B., and Stampanoni, M. (2016). Amyloid-beta plaque deposition measured using propagation-based X-ray phase contrast CT imaging. J. Synchrotron Radiat. 23, 813-819. doi: $10.1107 / \mathrm{s} 1600577516004045$

Barbone, G. E., Bravin, A., Romanelli, P., Mittone, A., Bucci, D., Gaabeta, T., et al. (2018). Micro-imaging of brain cancer radiation therapy using phasecontrast computed tomography. Int. J. Radiat. Oncol. Biol. Phys. 101, 965-984. doi: 10.1016/j.ijrobp.2018.03.063

Beckmann, F., Heise, K., Kolsch, B., Bonse, U., Rajewsky, M. F., Bartscher, M., et al. (1999). Three-dimensional imaging of nerve tissue by $\mathrm{x}$-ray phase-contrast microtomography. Biophys. J. 76, 98-102. doi: 10.1016/s0006-3495(99)77181-x

Bernard, C., Bajolle, A., Droulle, P., Didier, F., and Hoeffel, J. C. (1988). [MRI in the diagnosis of lissencephaly. Apropos of a case]. J. Radiol. 69, 691-695.

Bernard, C., Catheline, G., Dilharreguy, B., Couffinhal, T., Ledure, S., LassalleLagadec, S., et al. (2016). Cerebral changes and cognitive impairment after an ischemic heart disease: a multimodal MRI study. Brain Imaging Behav. 10, 893-900. doi: 10.1007/s11682-015-9483-4

Berning, M., Boergens, K. M., and Helmstaedter, M. (2015). SegEM: efficient image analysis for high-resolution connectomics. Neuron 87, 1193-1206. doi: 10.1016/j.neuron.2015.09.003

Betz, O., Wegst, U., Weide, D., Heethoff, M., Helfen, L., Lee, W. K., et al. (2007). Imaging applications of synchrotron X-ray phase-contrast microtomography in biological morphology and biomaterials science. I. General aspects of the technique and its advantages in the analysis of millimetre-sized arthropod structure. J. Microsc. 227, 51-71. doi: 10.1111/j.1365-2818.2007.01785.x brain and this will only be fulfilled with an integrative approach. In addition, image analysis demands further improvement to generate complete brain maps with cellular resolution and speed up the connectomics era.

Once accomplished, and with the new upcoming 4th generation of synchrotron-light sources in Europe and South America, imminent revolutionary contributions of $\mu \mathrm{CT}$ to the neurobiology field, from basic, clinical, and translational research, can be expected.

\section{AUTHOR CONTRIBUTIONS}

MF and CD supervised the study and conceptualized the idea. All authors wrote the manuscript, contributed to the article, and approved the submitted version.

\section{FUNDING}

The research was conducted with financial support from São Paulo Research Foundation (FAPESP, MF, grant 2018/20014-0 and 2021/01990-0, MF and BB, grant 2019/24511-0).

\section{ACKNOWLEDGMENTS}

We thank LNLS and LNBio/CNPEM for access to their core facilities. We also would like to thank Dr. Hernandes Faustino Carvalho for carefully reading this manuscript.

Bonse, U., Busch, F., Gunnewig, O., Beckmann, F., Pahl, R., Delling, G., et al. (1994). 3D computed X-ray tomography of human cancellous bone at 8 microns spatial and 10(-4) energy resolution. Bone Miner. 25, 25-38. doi: 10.1016/ s0169-6009(08)80205-x

Bravin, A., Coan, P., and Suortti, P. (2013). X-ray phase-contrast imaging: from pre-clinical applications towards clinics. Phys. Med. Biol. 58, R1-R35.

Bukreeva, I., Asadchikov, V., Buzmakov, A., Chukalina, M., Ingacheva, A., Korolev, N. A., et al. (2020). High resolution 3D visualization of the spinal cord in a postmortem murine model. Biomed. Opt. Express 11, 2235-2253. doi: 10.1364/boe. 386837

Bukreeva, I., Campi, G., Fratini, M., Spano, R., Bucci, D., Battaglia, G., et al. (2017). Quantitative 3D investigation of Neuronal network in mouse spinal cord model. Sci. Rep. 7:41054

Busse, M., Müller, M., Kimm, M. A., Ferstl, S., Allner, S., Achterhold, K., et al. (2017). Three-dimensional virtual histology enabled through cytoplasmspecific X-ray stain for microscopic and nanoscopic computed tomography. Proc. Natl. Acad. Sci. U.S.A. 115, 2293-2298. doi: 10.1073/pnas.1720862115

Carboni, E., Nicolas, J. D., Topperwien, M., Stadelmann-Nessler, C., Lingor, P., and Salditt, T. (2017). Imaging of neuronal tissues by x-ray diffraction and $\mathrm{x}$-ray fluorescence microscopy: evaluation of contrast and biomarkers for neurodegenerative diseases. Biomed. Opt. Express 8, 4331-4347. doi: 10.1364/ boe.8.004331

Cedola, A., Bravin, A., Bukreeva, I., Fratini, M., Pacureanu, A., Mittone, A., et al. (2017). X-ray phase contrast tomography reveals early vascular alterations and neuronal loss in a multiple sclerosis model. Sci. Rep. 7:5890.

Chen, J.-Y., Bottjer, D. J., Davidson, E. H., Li, G., Gao, F., Cameron, R. A., et al. (2009). Phase contrast synchrotron X-ray microtomography of Ediacaran (Doushantuo) metazoan microfossils: phylogenetic diversity and evolutionary implications. Precambrian Res. 173, 191-200. doi: 10.1016/j.precamres.2009. 04.004 
Chin, A.-L., Yang, S.-M., Chen, H.-H., Libc, M.-T., Lee, T.-T., Chen, Y.-J., et al. (2020). A synchrotron X-ray imaging strategy to map large animal brains. Chin. J. Phys. 65, 24-32. doi: 10.1016/j.cjph.2020.01.010

Collingwood, J. F., and Freddy, A. (2017). Chemical imaging analysis of the brain with X-ray methods. Spectrochim. Acta Part B Atom. Spectrosc. 130, 101-118. doi: 10.1016/j.sab.2017.02.013

Connor, D. M., Benveniste, H., Dilmanian, F. A., Kritzer, M. F., Miller, L. M., and Zhong, Z. (2009a). Computed tomography of amyloid plaques in a mouse model of Alzheimer's disease using diffraction enhanced imaging. Neuroimage 46, 908-914. doi: 10.1016/j.neuroimage.2009.03.019

Connor, D. M., Hallen, H. D., Lalush, D. S., Sumner, D. R., and Zhong, Z. (2009b). Comparison of diffraction-enhanced computed tomography and monochromatic synchrotron radiation computed tomography of human trabecular bone. Phys. Med. Biol. 54, 6123-6133. doi: 10.1088/0031-9155/54/ 20/006

Davis, G. R., Mills, D., and Anderson, P. (2018). Real-time observations of tooth demineralization in 3 dimensions using X-ray microtomography. J. Dent. 69, 88-92. doi: 10.1016/j.jdent.2017.11.010

de Bournonville, S., Vangrunderbeeck, S., and Kerckhofs, G. (2019). Contrastenhanced MicroCT for Virtual 3D anatomical pathology of biological tissues: a literature review. Contrast Media Mol. Imaging 2019:8617406.

de Crespigny, A., Bou-Reslan, H., Nishimura, M. C., Phillips, H., Carano, R. A., and D'arceuil, H. E. (2008). 3D micro-CT imaging of the postmortem brain. J. Neurosci. Methods 171, 207-213. doi: 10.1016/j.jneumeth.2008.03.006

Deng, J., Lo, Y. H., Gallagher-Jones, M., Chen, S., Pryor, A. Jr., Jin, Q., et al. (2018). Correlative 3D x-ray fluorescence and ptychographic tomography of frozen-hydrated green algae. Sci. Adv. 4:eaau4548. doi: 10.1126/sciadv.aau4548

Denk, W., and Horstmann, H. (2004). Serial block-face scanning electron microscopy to reconstruct three-dimensional tissue nanostructure. PLoS Biol. 2:e329. doi: 10.1371/journal.pbio.0020329

Depannemaecker, D., Santos, L. E. C., De Almeida, A. G., Ferreira, G. B. S., Baraldi, G. L., Miqueles, E. X., et al. (2019). Gold nanoparticles for X-ray microtomography of neurons. ACS Chem. Neurosci. 10, 3404-3408. doi: 10. 1021/acschemneuro.9b00290

Di Chiro, G., and Brooks, R. A. (1979). The 1979 Nobel prize in physiology or medicine. Science 206, 1060-1062. doi: 10.1126/science.386516

Dias, C. S. B., Neto, D. P. A., Baraldi, G. L., and Fonseca, M. C. (2019). Comparative analysis of sample preparation protocols of soft biological tissues for morphometric studies using synchrotron-based X-ray microtomography. J. Synchrotron Radiat. 26, 2013-2023. doi: 10.1107/s160057751901 1299

Dodt, H. U., Leischner, U., Schierloh, A., Jahrling, N., Mauch, C. P., Deininger, K., et al. (2007). Ultramicroscopy: three-dimensional visualization of neuronal networks in the whole mouse brain. Nat. Methods 4, 331-336. doi: 10.1038/ nmeth 1036

Dyer, E. L., Gray Roncal, W., Prasad, J. A., Fernandes, H. L., Gursoy, D., De Andrade, V., et al. (2017). Quantifying mesoscale neuroanatomy using X-ray microtomography. eNeuro 4:ENEURO.0195-17.2017.

Erturk, A., Becker, K., Jahrling, N., Mauch, C. P., Hojer, C. D., Egen, J. G., et al. (2012). Three-dimensional imaging of solvent-cleared organs using 3DISCO. Nat. Protoc. 7, 1983-1995. doi: 10.1038/nprot.2012.119

Erturk, A., and Bradke, F. (2013). High-resolution imaging of entire organs by 3dimensional imaging of solvent cleared organs (3DISCO). Exp. Neurol. 242, 57-64. doi: 10.1016/j.expneurol.2012.10.018

Erturk, A., Lafkas, D., and Chalouni, C. (2014). Imaging cleared intact biological systems at a cellular level by 3DISCO. J. Vis. Exp. 89:51382.

Flannery, B. P., Deckman, H. W., Roberge, W. G., and D'amico, K. L. (1987). Three-dimensional X-ray microtomography. Science 237, 1439-1444.

Fonseca, M. C., Araujo, B. H. S., Dias, C. S. B., Archilha, N. L., Neto, D. P. A., Cavalheiro, E., et al. (2018). High-resolution synchrotron-based $\mathrm{X}$-ray microtomography as a tool to unveil the three-dimensional neuronal architecture of the brain. Sci. Rep. 8:12074.

Fratini, M., Bukreeva, I., Campi, G., Brun, F., Tromba, G., Modregger, P., et al. (2015). Simultaneous submicrometric 3D imaging of the micro-vascular network and the neuronal system in a mouse spinal cord. Sci. Rep. 5:8514.

Fusseis, F., Regenauer-Lieb, K., Liu, J., Hough, R. M., and De Carlo, F. (2009). Creep cavitation can establish a dynamic granular fluid pump in ductile shear zones. Nature 459, 974-977. doi: 10.1038/nature08051
Gallagher-Jones, M., Dias, C. S. B., Pryor, A. Jr., Bouchmella, K., Zhao, L., Lo, Y. H., et al. (2017). Correlative cellular ptychography with functionalized nanoparticles at the Fe L-edge. Sci. Rep. 7:4757.

Ganesana, M., Lee, S. T., Wang, Y., and Venton, B. J. (2017). Analytical techniques in neuroscience: recent advances in imaging, separation, and electrochemical methods. Anal. Chem. 89, 314-341. doi: 10.1021/acs.analchem.6b04278

Glickstein, M. (2006). Golgi and Cajal: the neuron doctrine and the 100th anniversary of the 1906 Nobel Prize. Curr. Biol. 16, R147-R151.

Golgi, C. (1873). Sulla sostanza grigia del cervello. Gazetta Med. Ital. 33, 244-246.

Grutzendler, J., Yang, G., Pan, F., Parkhurst, C. N., and Gan, W.-B. (2011). Transcranial two-photon imaging of the living mouse brain. Cold Spring Harb. Protoc. 2011:10.1101/pdb.prot065474 pdb.prot065474.

Happel, C. M., Klose, C., Witton, G., Angrisani, G. L., Wienecke, S., Groos, S., et al. (2010). Non-destructive, high-resolution 3-dimensional visualization of a cardiac defect in the chick embryo resembling complex heart defect in humans using micro-computed tomography: double outlet right ventricle with left juxtaposition of atrial appendages. Circulation 122, e561-e564.

Hemonnot, C. Y. J., and Koster, S. (2017). Imaging of biological materials and cells by X-ray scattering and diffraction. ACS Nano 11, 8542-8559. doi: 10.1021/ acsnano.7b03447

Hieber, S. E., Bikis, C., Khimchenko, A., Schweighauser, G., Hench, J., Chicherova, N., et al. (2016). Tomographic brain imaging with nucleolar detail and automatic cell counting. Sci. Rep. 6:32156.

Holzner, C., Feser, M., Vogt, S., Hornberger, B., Baines, S. B., and Jacobsen, C. (2010). Zernike phase contrast in scanning microscopy with X-rays. Nat. Phys. 6, 883-887. doi: 10.1038/nphys 1765

Hounsfield, G. N. (1973). Computerized transverse axial scanning (tomography). 1. Description of system. Br. J. Radiol. 46, 1016-1022. doi: 10.1259/0007-128546-552-1016

Januszewski, M., Kornfeld, J., Li, P. H., Pope, A., Blakely, T., Lindsey, L., et al. (2018). High-precision automated reconstruction of neurons with flood-filling networks. Nat. Methods 15, 605-610. doi: 10.1038/s41592-018-0049-4

Johnson, J. T., Hansen, M. S., Wu, I., Healy, L. J., Johnson, C. R., Jones, G. M., et al. (2006). Virtual histology of transgenic mouse embryos for high-throughput phenotyping. PLoS Genet. 2:e61. doi: 10.1371/journal.pgen.0020061

Kamenz, C., and Weidemann, G. (2009). Heavy metal-a contrasting substance for micro-tomographical visualization of scorpion book lungs. Micron 40, 911-917. doi: 10.1016/j.micron.2009.05.007

Ke, M. T., and Imai, T. (2014). Optical clearing of fixed brain samples using SeeDB. Curr. Protoc. Neurosci. 66, 2.22.1-2.22.19.

Khimchenko, A., Bikis, C., Pacureanu, A., Hieber, S. E., Thalmann, P., Deyhle, H., et al. (2018). Hard X-Ray nanoholotomography: large-scale, label-free, 3D neuroimaging beyond optical limit. Adv. Sci. 5:1700694. doi: 10.1002/advs. 201700694

Kim, J., Chhour, P., Hsu, J., Litt, H. I., Ferrari, V. A., Popovtzer, R., et al. (2017). Use of nanoparticle contrast agents for cell tracking with computed tomography. Bioconjug. Chem. 28, 1581-1597. doi: 10.1021/acs.bioconjchem.7b00194

Knott, G., Marchman, H., Wall, D., and Lich, B. (2008). Serial section scanning electron microscopy of adult brain tissue using focused ion beam milling. J. Neurosci. 28, 2959-2964. doi: 10.1523/jneurosci.3189-07.2008

Koveal, D., Díaz-García, C. M., and Yellen, G. (2020). Fluorescent biosensors for neuronal metabolism and the challenges of quantitation. Curr. Opin. Neurobiol. 63, 111-121. doi: 10.1016/j.conb.2020.02.011

Kuehne, T., Yilmaz, S., Steendijk, P., Moore, P., Groenink, M., Saaed, M., et al. (2004). Magnetic resonance imaging analysis of right ventricular pressurevolume loops: in vivo validation and clinical application in patients with pulmonary hypertension. Circulation 110, 2010-2016. doi: 10.1161/01.cir. 0000143138.02493.dd

Kuwajima, T., Sitko, A. A., Bhansali, P., Jurgens, C., Guido, W., and Mason, C. (2013). ClearT: a detergent- and solvent-free clearing method for neuronal and non-neuronal tissue. Development 140, 1364-1368. doi: 10.1242/dev.091844

Lanzirotti, A., Sutton, S. R., Rivers, M., and Tappero, R. (2009). Synchrotron X-ray Fluorescence Microtomography in Geo-, Cosmo-, and Bio-Chemistry. Available online at: https://ui.adsabs.harvard.edu/abs/2009AGUSM.V74A..02L/abstract (accessed October 11, 2020).

Li, J., Chaudhary, A., Chmura, S. J., Pelizzari, C., Rajh, T., Wietholt, C., et al. (2010). A novel functional CT contrast agent for molecular imaging of cancer. Phys. Med. Biol. 55, 4389-4397. doi: 10.1088/0031-9155/55/15/013 
Litzlbauer, H. D., Neuhaeuser, C., Moell, A., Greschus, S., Breithecker, A., Franke, F. E., et al. (2006). Three-dimensional imaging and morphometric analysis of alveolar tissue from microfocal X-ray-computed tomography. Am. J. Physiol. Lung. Cell. Mol. Physiol. 291, L535-L545.

Lo, Y. H., Zhao, L., Gallagher-Jones, M., Rana, A., Xiao, W., Regan, B. C., et al. (2018). In situ coherent diffractive imaging. Nat. Commun. 9:1826.

Luo, Y., Yin, X., Shi, S., Ren, X., Zhang, H., Wang, Z., et al. (2019). Non-destructive 3D microtomography of cerebral angioarchitecture changes following ischemic stroke in rats using synchrotron radiation. Front. Neuroanat. 13:5. doi: 10.3389/ fnana.2019.00005

Masis, J., Mankus, D., Wolff, S. B. E., Guitchounts, G., Joesch, M., and Cox, D. D. (2018). A micro-CT-based method for quantitative brain lesion characterization and electrode localization. Sci. Rep. 8:5184.

Massimi, L., Bukreeva, I., Santamaria, G., Fratini, M., Corbelli, A., Brun, F., et al. (2019). Exploring Alzheimer's disease mouse brain through X-ray phase contrast tomography: from the cell to the organ. Neuroimage 184, 490-495. doi: 10.1016/j.neuroimage.2018.09.044

Md Khudzari, J., Wagiran, H., Hossain, I., and Ibrahim, N. (2013). Screening heavy metals levels in hair of sanitation workers by X-ray fluorescence analysis. J. Environ. Radioact. 115, 1-5. doi: 10.1016/j.jenvrad.2012.05.013

Metscher, B. D. (2009). MicroCT for comparative morphology: simple staining methods allow high-contrast 3D imaging of diverse non-mineralized animal tissues. BMC Physiol. 9:11. doi: 10.1186/1472-6793-9-11

Micheva, K. D., and Smith, S. J. (2007). Array tomography: a new tool for imaging the molecular architecture and ultrastructure of neural circuits. Neuron 55, 25-36. doi: 10.1016/j.neuron.2007.06.014

Mizutani, R., Takeuchi, A., Hara, T., Uesugi, K., and Suzuki, Y. (2007). Computed tomography imaging of the neuronal structure of Drosophila brain. J. Synchrotron Radiat. 14, 282-287.

Mizutani, R., Takeuchi, A., Uesugi, K., Takekoshi, S., Osamura, R. Y., and Suzuki, Y. (2008). X-ray microtomographic imaging of three-dimensional structure of soft tissues. Tissue Eng. Part C Methods 14, 359-363. doi: 10.1089/ten.tec.2008.0274

Mizutani, R., Takeuchi, A., Uesugi, K., Takekoshi, S., Osamura, R. Y., and Suzuki, Y. (2010). Microtomographic analysis of neuronal circuits of human brain. Cereb. Cortex 20, 1739-1748. doi: 10.1093/cercor/bhp237

Motta, A., Berning, M., Boergens, K. M., Staffler, B., Beining, M., Loomba, S., et al. (2019). Dense connectomic reconstruction in layer 4 of the somatosensory cortex. Science 366:eaay3134. doi: 10.1126/science.aay3134

Naha, P. C., Zaki, A. A., Hecht, E., Chorny, M., Chhour, P., Blankemeyer, E., et al. (2014). Dextran coated bismuth-iron oxide nanohybrid contrast agents for computed tomography and magnetic resonance imaging. J. Mater. Chem. B 2, 8239-8248. doi: 10.1039/c4tb01159g

Nakasako, M., Kobayashi, A., Takayama, Y., Asakura, K., Oide, M., Okajima, K., et al. (2020). Methods and application of coherent X-ray diffraction imaging of noncrystalline particles. Biophys. Rev. 12, 541-567. doi: 10.1007/s12551-02000690-9

Nani, J. V., Fonseca, M. C., Engi, S. A., Perillo, M. G., Dias, C. S., Gazarini, M. L., et al. (2020). Decreased nuclear distribution nudE-like 1 enzyme activity in an animal model with dysfunctional disrupted-in-schizophrenia 1 signaling featuring aberrant neurodevelopment and amphetamine-supersensitivity. J. Psychopharmacol. 34, 467-477. doi: 10.1177/0269881119897562

Neues, F., and Epple, M. (2008). X-ray microcomputer tomography for the study of biomineralized endo- and exoskeletons of animals. Chem. Rev. 108, 4734-4741. doi: $10.1021 / \mathrm{cr} 078250 \mathrm{~m}$

Nimmerjahn, A. (2012). Two-photon imaging of microglia in the mouse cortex in vivo. Cold Spring Harb. Protoc. 2012:pdb.prot069294. doi: 10.1101/pdb. prot069294

Oheim, M., Beaurepaire, E., Chaigneau, E., Mertz, J., and Charpak, S. (2001). Twophoton microscopy in brain tissue: parameters influencing the imaging depth. J. Neurosci. Methods 111, 29-37. doi: 10.1016/s0165-0270(01)00438-1

Ortega, R., Cloetens, P., Deves, G., Carmona, A., and Bohic, S. (2007). Iron storage within dopamine neurovesicles revealed by chemical nano-imaging. PLoS One 2:e925. doi: 10.1371/journal.pone.0000925

Padole, A., Ali Khawaja, R. D., Kalra, M. K., and Singh, S. (2015). CT radiation dose and iterative reconstruction techniques. AJR Am. J. Roentgenol. 204, W384-W392.

Parameswaran, H., Bartolak-Suki, E., Hamakawa, H., Majumdar, A., Allen, P. G., and Suki, B. (2009). Three-dimensional measurement of alveolar airspace volumes in normal and emphysematous lungs using micro-CT. J. Appl. Physiol. 107, 583-592. doi: 10.1152/japplphysiol.91227.2008

Ramón y Cajal, S. (1911). Histologie du Système Nerveux de L'homme \& des Vertébrés: Cervelet, Cerveau Moyen, Rétine, Couche Optique, Corps Strié, Écorce Cérébrale Générale \& Régionale, Grand Sympathique. Paris: HACHETTE BNF.

Saiga, R., Hoshino, M., Takeuchi, A., Uesugi, K., Naitou, K., Kamijo, A., et al. (2019). Synchrotron radiation microtomography of brain hemisphere and spinal cord of a mouse model of multiple sclerosis revealed a correlation between capillary dilation and clinical score. J. Comp. Neurol. 527, 2091-2100. doi: 10.1002/cne.24544

Sakaguchi, R., Leiwe, M. N., and Imai, T. (2018). Bright multicolor labeling of neuronal circuits with fluorescent proteins and chemical tags. eLife 7:e40350.

Sakdinawat, A., and Attwood, D. (2010). Nanoscale X-ray imaging. Nat. Photonics 4, 840-848.

Salome, M., Peyrin, F., Cloetens, P., Odet, C., Laval-Jeantet, A. M., Baruchel, J., et al. (1999). A synchrotron radiation microtomography system for the analysis of trabecular bone samples. Med. Phys. 26, 2194-2204. doi: 10.1118/1.598736

Schulz, R. B., Ale, A., Sarantopoulos, A., Freyer, M., Soehngen, E., Zientkowska, M., et al. (2010). Hybrid system for simultaneous fluorescence and X-ray computed tomography. IEEE Trans. Med. Imaging 29, 465-473. doi: 10.1109/tmi.2009. 2035310

Schulze, R. K., Berndt, D., and D'hoedt, B. (2010). On cone-beam computed tomography artifacts induced by titanium implants. Clin. Oral Implants Res. 21, 100-107. doi: 10.1111/j.1600-0501.2009.01817.x

Shahmoradian, S. H., Tsai, E. H. R., Diaz, A., Guizar-Sicairos, M., Raabe, J., Spycher, L., et al. (2017). Three-dimensional imaging of biological tissue by Cryo X-Ray ptychography. Sci. Rep. 7:6291.

Shi, S., Zhang, H., Yin, X., Wang, Z., Tang, B., Luo, Y., et al. (2019). 3D digital anatomic angioarchitecture of the mouse brain using synchrotron-radiationbased propagation phase-contrast imaging. J. Synchrotron Radiat. 26, 17421750. doi: $10.1107 /$ s $160057751900674 x$

Smith, D. B., Bernhardt, G., Raine, N. E., Abel, R. L., Sykes, D., Ahmed, F., et al. (2016). Exploring miniature insect brains using micro-CT scanning techniques. Sci. Rep. 6:21768.

Stockmar, M., Hubert, M., Dierolf, M., Enders, B., Clare, R., Allner, S., et al. (2015). X-ray nanotomography using near-field ptychography. Opt. Express 23, 12720-12731. doi: 10.1364/oe.23.012720

Swindell, W., and Barrett, H. H. (1977). Computerized tomography taking sectional X rays. Phys. Today 30, 32-41. doi: 10.1063/1.3037825

Swy, E. R., Schwartz-Duval, A. S., Shuboni, D. D., Latourette, M. T., Mallet, C. L., Parys, M., et al. (2014). Dual-modality, fluorescent, PLGA encapsulated bismuth nanoparticles for molecular and cellular fluorescence imaging and computed tomography. Nanoscale 6, 13104-13112. doi: 10.1039/c4nr01405g

Takashima, K., Hoshino, M., Uesugi, K., Yagi, N., Matsuda, S., Nakahira, A., et al. (2015). X-ray phase-contrast computed tomography visualizes the microstructure and degradation profile of implanted biodegradable scaffolds after spinal cord injury. J. Synchrotron Radiat. 22, 136-142. doi: 10.1107/ s160057751402270x

Tapia, J. C., Kasthuri, N., Hayworth, K. J., Schalek, R., Lichtman, J. W., Smith, S. J., et al. (2012). High-contrast en bloc staining of neuronal tissue for field emission scanning electron microscopy. Nat. Protoc. 7, 193-206. doi: 10.1038/ nprot.2011.439

Toda, H., Yamamoto, S., Kobayashi, M., Uesugi, K., and Zhang, H. (2008). Direct measurement procedure for three-dimensional local crack driving force using synchrotron X-ray microtomography. Acta Mater. 56, 6027-6039. doi: 10.1016/ j.actamat.2008.08.022

Topperwien, M., Doeppner, T. R., Zechmeister, B., Bahr, M., and Salditt, T. (2019). Multiscale $\mathrm{x}$-ray phase-contrast tomography in a mouse model of transient focal cerebral ischemia. Biomed. Opt. Express 10, 92-103. doi: 10.1364/boe.10.000092

Topperwien, M., Van Der Meer, F., Stadelmann, C., and Salditt, T. (2018). Threedimensional virtual histology of human cerebellum by X-ray phase-contrast tomography. Proc. Natl. Acad. Sci. U.S.A. 115, 6940-6945. doi: 10.1073/pnas. 1801678115

Tsuchiyama, A., Nakano, T., Uesugi, K., Uesugi, M., Takeuchi, A., Suzuki, Y., et al. (2013). Analytical dual-energy microtomography: a new method for obtaining three-dimensional mineral phase images and its application to Hayabusa samples. Geochim. Cosmochim. Acta 116, 5-16. doi: 10.1016/j.gca.2012.11.036 
van de Kamp, T., Vagovic, P., Baumbach, T., and Riedel, A. (2011). A biological screw in a beetle's leg. Science 333:52. doi: 10.1126/science.1204245

Vartiainen, I., Mohacsi, I., Stachnik, K., Guizar-Sicairos, M., David, C., and Meents, A. (2016). Zernike x-ray ptychography. Opt. Lett. 41, 721-724. doi: 10.1364/ol. 41.000721

Vartiainen, I., Warmer, M., Goeries, D., Herker, E., Reimer, R., David, C., et al. (2014). Towards tender X-rays with Zernike phase-contrast imaging of biological samples at $50 \mathrm{~nm}$ resolution. J. Synchrotron Radiat. 21, 790-794. doi: $10.1107 / \mathrm{s} 1600577514010388$

Vedantam, A., Jirjis, M., Eckhardt, G., Sharma, A., Schmit, B. D., Wang, M. C., et al. (2013). Diffusion tensor imaging of the spinal cord: a review. Coluna/Columna 12, 64-69.

Walker, S. M., Schwyn, D. A., Mokso, R., Wicklein, M., Muller, T., Doube, M., et al. (2014). In vivo time-resolved microtomography reveals the mechanics of the blowfly flight motor. PLoS Biol. 12:e1001823. doi: 10.1371/journal.pbio. 1001823

Wang, Z., Chen, L., Huang, C., Huang, Y., and Jia, N. (2017). Albumin-mediated platinum nanocrystals for in vivo enhanced computed tomography imaging. J. Mater. Chem. B 5, 3498-3510. doi: 10.1039/c7tb00561j

Weinhardt, V., Chen, J. H., Ekman, A., Mcdermott, G., Le Gros, M. A., and Larabell, C. (2019). Imaging cell morphology and physiology using X-rays. Biochem. Soc. Trans. 47, 489-508. doi: 10.1042/bst20180036

Yang, Y., Li, W., Liu, G., Zhang, X., Chen, J., Wu, W., et al. (2010). 3D visualization of subcellular structures of Schizosaccharomyces pombe by hard X-ray tomography. J. Microsc. 240, 14-20. doi: 10.1111/j.1365-2818.2010. 03379.x

Zhang, M. Q., Zhou, L., Deng, Q. F., Xie, Y. Y., Xiao, T. Q., Cao, Y. Z., et al. (2015). Ultra-high-resolution 3D digitalized imaging of the cerebral angioarchitecture in rats using synchrotron radiation. Sci. Rep. 5:14982.
Zhang, W., and Fuller, R. G. (1998). Nobel prize winners in physics from 1901 to 1990: simple statistics for physics teachers. Phys. Educ. 33:196. doi: 10.1088/ 0031-9120/33/3/023

Zhu, J., Zheng, L., Wen, S., Tang, Y., Shen, M., Zhang, G., et al. (2014). Targeted cancer theranostics using alpha-tocopheryl succinateconjugated multifunctional dendrimer-entrapped gold nanoparticles. Biomaterials 35, 7635-7646. doi: 10.1016/j.biomaterials.2014. 05.046

Zhu, W., Gaetani, G. A., Fusseis, F., Montesi, L. G., and De Carlo, F. (2011). Microtomography of partially molten rocks: three-dimensional melt distribution in mantle peridotite. Science 332, 88-91. doi: 10.1126/science. 1202221

Zou, X., Liu, D., Yue, L., and Wu, M. (2011). The ability of cone-beam computerized tomography to detect vertical root fractures in endodontically treated and nonendodontically treated teeth: a report of 3 cases. Oral Surg. Oral Med. Oral Pathol. Oral Radiol. Endod. 111, 797-801. doi: 10.1016/j.tripleo.2010. 12.015

Conflict of Interest: The authors declare that the research was conducted in the absence of any commercial or financial relationships that could be construed as a potential conflict of interest.

Copyright (c) 2021 Rodrigues, Tostes, Bosque, Godoy, Amorim Neto, Dias and Fonseca. This is an open-access article distributed under the terms of the Creative Commons Attribution License (CC BY). The use, distribution or reproduction in other forums is permitted, provided the original author(s) and the copyright owner(s) are credited and that the original publication in this journal is cited, in accordance with accepted academic practice. No use, distribution or reproduction is permitted which does not comply with these terms. 